\section{Cortical and spinal excitability}

Sir: I wish to comment on the report of reduced cortical excitability in depression (Shajahan et al, 1999).

First, the amount of time the subjects spent on exercising the muscle group was not stated. It is important for the exercise regime to be clearly stated so that the study can be replicated.

Second, it is believed that magnetic stimuli excite the cortex and the axon hillocks of the output neurons, whereas electrical stimuli directly excite corticospinal axons (Mills \& Kimiskidis, 1996). It follows that the size of electrically evoked responses will reflect predominantly spinal motorneuron excitability, whereas magnetically evoked responses will reflect both cortical and spinal excitability. Hallett (1996) indicates that it is possible to control for changes of excitability downstream from the cortical network, by using transcranial electrical stimulation, which stimulates the descending axons directly. Armand et al (1996) also show that if a corticospinal volley is evoked by transcranial magnetic stimulation (TMS), the electromyogram (EMG) response that results from it occurs after a certain delay including a central and peripheral conduction time. In most human studies, the central motor conduction time has been estimated by subtracting, from the latency of EMG response to TMS recorded in a given muscle, the latency of the responses excited by magnetic stimulation over the cervical spines. The latter is thought to excite the peripheral motor axons as they leave the vertebral column, and thus gives an estimate of the peripheral conduction time. Subtraction of this value allows the central motor conduction time to be calculated. In my opinion, the study design used by Shajahan et al is flawed as it fails to account for excitability at the spinal level.

Armand, J., Olivier, E., Ed,des S. A., et of (ISs) The structure and function of the developing corticospinal tract. In Hand and Broin: The Neurophysiology and Psychology of Hand Movement (eds A. M.Wing, P. Haggard \& J. R. Flanagan), pp. 125-145. London: Academic Press.

Halleta, M. (19\%) Transcranial magnetic stimulation: a useful tool for clinical neurophysiology. Annals of Neunology, 10, 344-345.

Muls, K. R. A KImidddi, V. (19\%) Motor cortex excitability during ballistic forearm and finger movements. Muscle and Nerve, 19, 468-473. Shajhan, P M, Ghabus, M. F, Cooding, P, ef ef (1999) Reduced cortical excitability in depression. Impaired postexercise motor facilitation with transcranial magnetic stimulation. British foumal of Pychiatry, 174, 449-454.

B.Y. Ng Department of Adult Psychiatry 2, Woodbridge Hospital and Institute of Mental Health, 10 Buangkok Green, Singapore 539747
Authors'reply: Dr $\mathrm{Ng}$ provides the very argument why post-exercise facilitation after transcranial magnetic stimulation (TMS) is a central rather than a peripheral phenomenon: transcranial electrically evoked responses reflect the stimulation of the descending axons only, while TMS acts trans-synaptically and by stimulating the axon near the cell body and is, therefore, dependent on the sum of all synaptic inputs to that neuron. As transcranial electrical stimulation demonstrates neither post-exercise facilitation nor depression, but TMS does, we are likely to be looking at central cortical excitability, rather than 'spinal excitability' (Samil et el, 1997). We have since shown that the reduced cortical excitability in depression is actually reversible with recovery from depression, independently of medication effects (Shajahan et al, 1999).

Exercise during the experiments was at $20 \%$ of maximum voluntary contraction for $30 \mathrm{~s}$ at a time. The procedure was repeated altogether five times. Any further details of the experimental set-up are available upon request from the authors.

Samil, A., Waseermann, E. M. \& Hallett, M. (I9)7) Decreased postexercise facilitation of motor evoked potentials in patients with cerebellar degeneration. Neurology, 49, 538-542.

Shaluhan, P. M., Chabus, M. E., Jenidins, J, et of (1999) Post-exercise motor evoked potentials in depressed, recovered depressed and controls. Neurology, in press.

P. Shajahan, M. Glabus, K. Ebmeler MRC Brain Metabolism Unit, Royal Edinburgh Hospital, Morningside Park, Edinburgh EHIO 5HF

\section{Ethnicity and first year of contact with psychiatric services}

Sir: The reports of Goater et al (1999) and Harrison et al (1999) seem to converge on the point that the course and outcome of first-onset psychotic illness are not significantly different in White and AfricanCaribbean populations in Britain. In both papers, the authors wisely caution against being too conclusive regarding their findings because of the small size of their respective samples.

In spite of the final consistency of the symptoms and diagnoses at the end of the follow-up periods, it is clear that the first year is central to the future interaction of the patients of African-Caribbean origin with psychiatric services. After one year, there were large relative increases in both psychotic and non-psychotic symptoms for the Black Caribbean patients and no convincing explanation is offered for this escalation of psychopathology that occurs during the first year of contact. The relationship between appropriateness and adequacy of treatment, compliance and phenomenology clearly needs to be investigated further. Goater et al (1999) suggest the increasing rate of conversion to schizophrenia and poorer compliance as plausible reasons for the adverse contacts that the Black patients have with psychiatric services in the fifth year of follow-up, in spite of the similar course. However, with similar modes of entry at first contact, it is likely that poor compliance would be a consequence rather than a cause of these problems. Both papers also point to a trend for a greater rate of changes in diagnoses among the African-Caribbean patients with the tendency to conversion to schizophrenia being strongest. Therefore, one wonders whether the experience of the service itself is schizophrenogenic for Black patients and, therefore, invites the future perceptions of abnormalities in speech, affect and behaviour which are more likely to meet criteria for schizophrenia and require more coercive means of management.

Research now needs to focus on the course of therapeutic intervention as generic approaches of management of psychotic illness may need to be reviewed to include both non-psychotic and psychotic symptoms. Comparisons with White British patients may not be entirely useful in these circumstances. This is reflected in the relative instability of both 'other' and 'schizophrenia' diagnoses for the Black patients compared with the White/Other groups. Finally, demographic categories need to be carefully constructed so that within-group differences can be examined more thoroughly.

Coater, N., King, M. Cole, E., et of (IS\%) Ethnicity and outcome of psychosis. British fournd of Psychiotry. 175, 34-42.

Harricon, G., Amln, S., Singh, S. P., et ol (1999) Outcome of psychosis in people of African-Caribbean family origin. Population-based first-episode study. British journal of Psychiatry, 175, 43-49.

G. Hutchinson, M. Sharpley Social Psychiatry Section, Institute of Psychiatry, De Crespigny Park, Denmark Hill, London SE5 8AF

\section{Psychiatry and homosexuality}

Sir: King \& Bartlett's (1999) review is both frank and commendable. They rightly 
conclude that mental health professionals "should be aware of the mistakes of the past".

I would like to point out that comparable mistakes continue in many parts of the world where homosexuality is still pathologised and substantially stigmatised. For example, according to the second revised edition of the Chinese Classification of Mental Disorders published in 1995, homosexuality remains a diagnosable psychiatric disease in China (Lee, 1996). A senior professor argued that this is because there is a lack of either biological or psychological evidence to show that homosexuality is 'absolutely normal' and that some homosexual people do seek medical or psychological help (Young, 1994). However, Lau \& $\mathrm{Ng}$ (1989) maintained that homosexuality not only has a long history but is also common in Chinese society.

In the USA the diagnostic category of 'egodystonic homosexuality' was not deleted from the DSM system until recently (American Psychiatric Association, 1987). It remains to be seen whether China's rapid economic reforms and admittedly more sluggish political liberalisation will lead to the de-pathologisation of homosexuality and the ripening of the Chinese gay community.

American Pupchiatric Aswockation (19e7) Diognostic and Statistical Manual of Mentol Disonders (3rd edn, revised) (DSM-III-R). Washington, DC: APA.

KIn, M. \& Bartlett, A. (1999) British psychiatry and homosexuality. British foumal of Psychiatry 175, 106-113.

Lau, M. P. N Ng, M. L. (I98s) Homosexuality in Chinese culture. Culture, Medicine and Psychiatry, I3. 465-488.

Lee, S. (199) Cultures in psychiatric nosology: the CCMD-2-R and international classification of mental disorders. Culture, Medicine \& Psychiotry 20, 421-472.

Young, $\mathbf{D}$ (19\%4) A personal view on the publication of the CCMD-2-R (in Chinese). Joumal of Clinical Psychological Medicine, 4, 221-223.

S. Lee Department of Psychiatry, Prince of Wales Hospital, Shatin, Hong Kong

Sir: King \& Bartlett (1999) outline the generally unhappy relationship between British psychiatry and homosexuality. Although British psychiatry never embraced psychoanalysis as in the USA, it still produced its own crop of negative and even homophobic theorising and practice. O'Connor \& Ryan (1993) have mapped out the work to be done for psychoanalytic psychotherapy from a lesbian perspective and I have attempted a smaller-scale exercise for gay men (Ratigan, 1998). We still have a long way to go to match the confidence of the lesbian and gay critiques of both psychiatry and psychoanalysis to be found in the USA (Cabaj \& Stein, 1996).

Working in a specialist National Health Service psychotherapy unit as a psychoanalytic psychotherapist, who happens to be gay, I come across gay men and lesbians who, while being generally content with their sexual orientations, nevertheless have major mental health problems, including personality disorders or perversions. I do not assume that homosexuality is a perversion per se; but there are gays and lesbians and heterosexuals with perversions.

At a recent conference at University College London on 'Narcissism and perversion: modern Kleinian perspectives' none of the clinical material was from the psychotherapies of gay or lesbian patients. It was as if it was not safe publicly to talk about gay or lesbian patients with perverse or narcissistic character structures for fear of being accused of homophobia. This was a pity as it deprives the lesbian and gay communities of current thinking in this area. I could not have imagined such a conference $\mathbf{1 0}$ years ago omitting homosexual material - there would have probably been little else.

Attempts to develop a lesbian and gay affirmative stance in psychotherapy are currently being proposed; it is a liberal not a radical response. Psychoanalysis needs to be challenged to return to its roots and regard all sexualities as problematic. Too much would be lost if we surrendered (the attempt at) therapeutic neutrality in psychoanalytic psychotherapy, especially in work with gay or lesbian patients with major mental health problems.

Cably, R. P. \& stein, T. S. (I9\%) Textbook of Homosexuality and Mental Health. Washington, DC: American Psychiatric Press.

KIng, M. \& Bartlett, A. (1999) British psychiatry and homosexuality. British journal of Psychiatry, 175, 106-113.

O'Connor, N. \& Ryan, J. (1993) Wild Desires and Mistaken Identities: Lesbionism and Psychoonolysis. London: Virago.

Ratigan, B. (1999) Gay men and psychoanalysis: queer bedfellows? In Contemporory Perspectives on Psychotheropy and Homosexualities (ed. C. Shelley). pp. 58-86. London: Free Association Books.

B. Ratigan Nottingham Psychotherapy Unit, St Ann's House, 114 Thorneywood Mount, Nottingham NG3 2PZ

\section{Old age forensic psychiatry}

Sir: The close collaborative working relationship that Gairin \& Quinn (1999) describe between the Yorkshire forensic and old age psychiatry services is interesting and could possibly serve as a model for how services might be organised elsewhere.

The relationship they describe, however, is far from universal and this is precisely the point of my editorial (Yorston, 1999) that psychiatric services for elderly mentally disordered offenders are patchy and uncoordinated with little or no research literature to act as a base for decision-making.

The fact that the number of elderly offenders is small (i.e. there is little demand) should no longer be accepted as a reason for neglecting this group. Whether there is a need for old age forensic psychiatry should be the question that is asked. In my experience, and that of many other old age and forensic psychiatrists, this need clearly exists and is inadequately met in many areas.

The way forward must surely involve more research in this area to determine need, and more debate of the various local solutions that have been found to meet it.

Gairin, L. \& Quinn, P. (1999) Old age forensic psychiatry. British joumal of Psychiotry, 175, 190.

Yorston, C. (1999) Aged and dangerous. Old age forensic psychiatry. British fournal of Psychiatry 174, 193-195.

G. Yorston Udston Hospital, Farm Road, Hamilton ML3 9LA

\section{Serving the interests of the Journol's readers}

Sir: It is genuinely encouraging to see how the Journal is now supporting parallel publication of electronic and paper systematic reviews relating to the care of people with mental health problems (Chalmers, 1999). Other journals have been doing this for a while (Johnstone \& Zolese, 1999; Soares \& McGrath, 1999; Wahlbeck et al, 1999).

We hope this also heralds a sea change in policy regarding treatment reviews in the Joumal. In January-July 1999 the Journal published its randomised trials, all, of course, with a Methods section, encouraging the view that these were as objectively undertaken as possible. Nine of the 15 trials were clearly industry sponsored, which is probably a similar rate to other key joumals. 